\title{
Ionothermal preparation of triclinic SAPO-34 and its catalytic performance in the MTO process
}

Manuel Sánchez-Sánchez*, Álvaro A. Romero, Irene Pinilla-Herrero and Enrique

Sastre*

Instituto de Catálisis y Petroleoquímica (ICP), CSIC, C/ Marie Curie 2, 28049 Madrid, Spain

Corresponding Authors:

Dr. Manuel Sánchez-Sanchez. E-mail address: manuel.sanchez@icp.csic.es

Telephone: +34-915854795. Fax: +34-915854760.

Dr. Enrique Sastre. E-mail address: esastre@icp.csic.es

Telephone: +34-915854795. Fax: +34-915854760.

KEYWORDS. Triclinic SAPO-34, V-doped, ionothermal, methanol-to-olefins, selectivity to olefins, hydrated SAPO-34. 


\section{ABSTRACT}

This work reports the ionothermal synthesis of SAPO-34 material, which is the perexcellence catalyst in the methanol-to-olefins (MTO) process. The direct addition of Si sources to the aluminophosphate and ionic liquid (1-ethyl-3-methyl imidazolium) mixture gave rise to the undesired AEL-structured materials. Therefore, some other strategies were necessary to apply. In particular, two unexplored strategies have been developed: (i) the addition of further heteroatom ions able to direct CHA materials, $\mathrm{V}$ ions being particularly efficient; and (ii) to carry out the synthesis in open systems rather than in autoclaves under autogenous pressure. Interestingly, the combination of both strategies led to $\mathrm{V}^{4+}$-free SAPO-34 samples, so any Brönsted acidity of the samples should be assigned to the incorporated $\mathrm{Si}$ atoms. These materials, far from being conventional SAPO-34, have triclinic CHA structure, which provides some structural singularities and has not been tested as catalyst in the MTO reaction yet. Despite their conversion level achieved was lower than that given by conventional SAPO-34, probably because of the scarce optimization of the physicochemical properties of the material, the selectivity towards the different olefins is interestingly different, favoring $\mathrm{C} 4$ olefins at the expense of ethylene and propylene. 


\section{Introduction}

Crystalline inorganic microporous materials, i.e. zeolites and zeotypes, are the catalysts with the highest volume of production because of their vast use in Refining, Petrochemistry and Fine Chemistry [1]. However, their preparation, almost exclusively based on hydrothermal processes [2], is far from the sustainable criteria imposed by an increasingly rigorous legislation and social awareness. In this context, scientific community is dedicating strong efforts in the sustainable preparation of zeolitic materials [3].

Ionic liquids (ILs) are considered as 'green' solvents for a great number of processes due to their potential recyclability and their extraordinary low vapor pressure [4]. The methods based on the use of ILs as media for the synthesis of materials are called ionothermal methods. In the case of zeolitic materials, ionothermal methods provides two key additional advantages: (i) the IL itself can act as structure-directing agent (SDA) $[5,6]$, which are commonly expensive, generally hazardous chemicals and are always added in a great excess with respect to the amount of SDA molecules finally found within the pores; and (ii) the crystallization of the materials can be carried out in open systems (autoclaves are not needed) because of the low vapor pressure of the IL.

The first publications about the synthesis of $\mathrm{AlPO}_{4}$-based zeotype materials in ionothermal media $[5,6]$ seemed to have as a background the possibility of extending these methods to zeolites, which are more demanded industrially. However, the achievement of these silica-based materials under ionothermal conditions was found to be less viable chemically. Different zeolites have been easily obtained using IL cations as SDAs under hydrothermal conditions [7-9], even producing new chiral zeolites [10]. Finally, certain pure silica zeolites could be synthesized under ionothermal treatment, 
with the ionic liquid playing both roles, solvent and SDA. That synthesis was a quite challenging task as it had to be preceded by the preparation of IL with a nonstoichiometric mixture of inorganic ions, one of them being necessarily $\mathrm{OH}^{-}[11]$.

The viability for incorporating $\mathrm{Si}$ in microporous materials crystallized ionothermally has been also made clear with the achievement of SAPO-5 in a eutectic mixture [12]. However, the homologous material SAPO-34 having much more industrial potential for being nowadays the per-excellence catalyst of the transformation of methanol into olefins (MTO process) [13-22], has scarcely described under ionothermal conditions so far, although it could be achieved under aminothermal conditions in the presence of very low water content [23]. To the best of our knowledge, the only described synthesis of SAPO-34 in IL media was described in a Chinese patent [24]. Nevertheless, the ionothermal preparation of some $\mathrm{Si}$-free $\mathrm{AlPO}_{4}-34$, the $\mathrm{AlPO}_{4}$-based materials called SIZ-4 [5] and SIZ-10 [25] (CHA) structure) has been widely described. In fact, CHAstructured materials are the AlPOs materials that can be prepared in a more varied ionothermal media [25]. Amongst that variety, the IL cation 1-ethyl-3-methyl imidazolium (EMI) has been selected in this work because of its commercially available, its relatively low price, its stability and the most common IL in the synthesis of $\mathrm{AlPO}_{4}-34[5,25]$.

The industrial and socioeconomic interest for MTO process (and, thus, for SAPO-34) is evidenced by the recent implantation of nine industrial plants based on this process in China in the last five years, which produce more than 5 million tons a year [26]. Because of that, this work does not only focus on the developing a more sustainable preparation of SAPO-34 but it also investigates the catalytic evaluation of these catalysts in the MTO process as well as the comparison of their catalytic behavior with that given by the conventional SAPO-34 [17]. This study shows the complexity of 
achieving SAPO-34 by direct synthesis under ionothermal conditions, that is, by simply addition of $\mathrm{Si}$ to the aluminophosphate gels. The use of two different synthesis strategies (using $\mathrm{V}$ as co-dopant and carrying out the synthesis in an open system) allowed overcoming such difficulties. The combination of both strategies led to $\mathrm{V}^{4+}$-free SAPO-34 materials that crystallize in triclinic spatial group (unlike the conventional trigonal SAPO-34). That structural difference, which is maintained after both calcination and reaction processes, had clear consequences in MTO processes, giving higher selectivity to $\mathrm{C} 4$ olefins.

\section{Experimental}

\subsection{Synthesis of SAPO-34 materials}

All the materials synthesis procedures were based on the methods described by Morris et al. for the CHA-structured $\mathrm{AlPO}_{4}$-based material SIZ-4 [5]. In all cases, $\mathrm{H}_{3} \mathrm{PO}_{4}(85$ wt. \% aqueous solution), aluminum isopropoxide, and HF (48 wt. \%) were used as sources of P, Al and F, respectively. 1-Ethyl-3-Methyl-Imidazolium (EMI) chloride was used as both solvent and structure-directing agent. The starting molar composition was $1.0 \mathrm{Al}: 3.0 \mathrm{P}: 0.73 \mathrm{HF}: 39 \mathrm{EMI}$. Water was not directly added in the synthesis gel, although it was present as diluent of both phosphoric and hydrofluoric acids. This method was modified by the direct addition of two different $\mathrm{Si}$ sources to give a $\mathrm{Si} / \mathrm{Al}$ molar ratio of 0.3 in the final mixture. The two Si sources were: (i) Aersoil 200 fumed silica (sample Si0.3), and (ii) tetraethyl orthosilicate -TEOS- (sample Si0.3T). Using Aerosil 200 as Si source, variations in the thermal pretreatment of the gel were also studied: $50{ }^{\circ} \mathrm{C}$ for 2 hours (sample Si0.3-50C), just like it was described in the literature for the material SIZ-4 [5], and $75^{\circ} \mathrm{C}$ for 2 hours (sample Si0.3-75C). The gels were 
introduced into Teflon-lined stainless steel autoclaves and ionothermally treated at 150 ${ }^{\circ} \mathrm{C}$ for 72 hours. During such treatment, the autoclaves were either closed under autogeneous pressure or open (see Results and discussion section for details). After the crystallization processes, the solids were filtered and washed with distilled water and subsequently with ethanol.

TAPO-34 and VAPO-34 materials were prepared adding titanium tetraisopropoxide (sample Ti0.04) and $\mathrm{VCl}_{3}(\mathrm{~V} 0.04)$, respectively, to the $\mathrm{AlPO}_{4}$ gel, with a (Ti or V)/Al ratio of 0.04 .

VAPSO-34 materials were prepared adding $\mathrm{VCl}_{3}$ and Aerosil 200 as $\mathrm{V}$ and Si sources to the $\mathrm{AlPO}_{4}$ gel. These samples were denoted as $\mathrm{V} n \mathrm{Si} m$, where $n$ and $m$ indicates the $\mathrm{V} / \mathrm{Al}$ and $\mathrm{Si} / \mathrm{Al}$ ratios, respectively. To identify the samples ionothermally crystallized in either open or closed autoclaves, the names of the samples will be finished with the letters 'op' or 'cl', respectively.

Before being tested as catalysts in MTO process, all materials were calcined at $550{ }^{\circ} \mathrm{C}$ for 6 hours under a dry air flow (100 $\mathrm{ml} / \mathrm{min})$.

Conventional SAPO-34 and $\mathrm{AlPO}_{4}-34$ materials, which were used for comparative purposes in this work, were prepared following procedures described elsewhere [27].

\subsection{Characterization techniques}

Powder X-ray diffraction (PXRD) patterns were collected with an X'Pert Pro PANalytical diffractometer $\left(\mathrm{CuK}_{\alpha 1}\right.$ radiation $\left.=0.15406 \mathrm{~nm}\right)$. UV-Vis Diffuse Reflectance Spectroscopy (DRS) measurements were run in a Varian Cary 5000 double- 
beam UV-Vis-NIR spectrophotometer. Collected spectra were converted to KubelkaMunk function, $\mathrm{F}(\mathrm{R})$, versus wavelength.

Ammonia temperature programmed desorption analyses $\left(\mathrm{NH}_{3}-\mathrm{TPD}\right)$ were performed as described elsewhere [28], using a Micrometrics Autochem II chemisorption analysis equipment. Typically, $100 \mathrm{mg}$ of sample pellets (30-40 mesh) were pretreated at $550{ }^{\circ} \mathrm{C}$ for $1 \mathrm{~h}$ in helium flow ( $25 \mathrm{~mL} / \mathrm{min})$ and then cooled to the adsorption temperature (177 $\left.{ }^{\circ} \mathrm{C}\right)$. A gas mixture of 5.0 vol. $\% \mathrm{NH}_{3}$ in $\mathrm{He}$ was then allowed to flow over the sample for $4 \mathrm{~h}$ at a rate of $15 \mathrm{~mL} / \mathrm{min}$. Afterwards, the sample was flushed with a $25 \mathrm{~mL} / \mathrm{min}$ helium flow for 30 min while maintaining the temperature at $177^{\circ} \mathrm{C}$ to remove weakly adsorbed $\mathrm{NH}_{3}$, and finally the temperature was increased to $550{ }^{\circ} \mathrm{C}$ at a rate of 10 ${ }^{\circ} \mathrm{C} / \mathrm{min}$.

All magic-angle spinning (MAS) nuclear magnetic resonance (NMR) spectra were acquired in a Bruker AV-400-WB spectrometer (9.4 T) operating at 104.26, 161.97, 100.6 and 376.3 MHz for registering ${ }^{27} \mathrm{Al},{ }^{31} \mathrm{P},{ }^{13} \mathrm{C}$ and ${ }^{19} \mathrm{~F}$ spectra, respectively. A 4mm probe and a spinning rate of $10 \mathrm{kHz}$ were used for all spectra of the three former nuclei and a $2.5-\mathrm{mm}$ probe for ${ }^{19} \mathrm{~F}$ spectra. ${ }^{27} \mathrm{Al}$ MAS NMR spectra were acquired by applying a pulse length of $0.4 \mu$ s corresponding to a flip angle of $\pi / 30$ and using a pulse delay of 2 s. The applied pulse length in the ${ }^{31} \mathrm{P}$ MAS NMR spectra was $3.0 \mu \mathrm{s}$ corresponding to a $\pi / 4$ flip angle and the pulse delay was $100 \mathrm{~s} .{ }^{1} \mathrm{H}$ to ${ }^{13} \mathrm{C}$ crosspolarization (CP) MAS NMR spectra were acquired by applying a $\pi / 2$ pulse of $3 \mu \mathrm{s}$ over the ${ }^{1} \mathrm{H}$ channel, using a contact time of $3.0 \mathrm{~ms}$ and a delay time between two consecutives pulses of 4 s. Finally, ${ }^{19}$ F MAS NMR spectra were registered applied a $\pi / 2$ pulse over the ${ }^{1} \mathrm{H}$ channel, with pulse delay of $60 \mathrm{~s} .{ }^{27} \mathrm{Al},{ }^{31} \mathrm{P},{ }^{13} \mathrm{C}$ and ${ }^{19} \mathrm{~F}$ chemical shifts were referenced to these of the primary reference $1 \mathrm{M} \mathrm{Al}\left(\mathrm{NO}_{3}\right)_{3}$ aqueous solution, $\mathrm{H}_{3} \mathrm{PO}_{4} 85 \%$, tetramethylsilane (TMS) and $\mathrm{CFCl}_{3}$, respectively. 
TG analyses were carried out at a heating rate of $20{ }^{\circ} \mathrm{C} / \mathrm{min}$ under air flow and registered in a PerkinElmer TGA7 instrument.

Nitrogen adsorption/desorption isotherms were measured at $-196{ }^{\circ} \mathrm{C}$ in a Micromeritics ASAP 2020 device. Before the measurement, the previously calcined sample was degassed at $350{ }^{\circ} \mathrm{C}$ under high vacuum for at least $18 \mathrm{~h}$. Surface areas were estimated by the BET method whereas microporous and external surface areas were estimated by applying the t-plot method.

For Scanning Electron Microscopy (SEM) analysis, the samples were coated with a gold film before being observed in a Field-Emission SEM (JEOL, SM-31010) microscope, also having a EDS detector for punctual/regional chemical analysis.

\subsection{MTO catalytic testing conditions}

Selected materials were tested as catalysts in the conversion of methanol to olefins at $400{ }^{\circ} \mathrm{C}$ in a Microactivity (PID Eng\&Tech) reaction equipment having a fix-bed reactor completely automatized and controlled from a computer. The reactor exit was connected

on-line to a gas chromatograph. $\mathrm{N}_{2}$ was used as inert dilution/drag gas under a controlled flow. Methanol was fed as liquid using a HPLC pump (Gilson 307). Next, it was vaporized and mixed with the $\mathrm{N}_{2}$ stream in a preheater at $180{ }^{\circ} \mathrm{C}$ in order to generate a gas mixture with a constant methanol/ $\mathrm{N}_{2}$ molar ratio of 1 . Prior to reaction, the catalysts were pretreated at $550{ }^{\circ} \mathrm{C}$ for 1 hour under air flow in order to remove any possible trace of organic moistures or adsorbed humidity within the catalyst pores. Any air traces after the thermal treatment was evacuated by flowing $\mathrm{N}_{2}$ at $400{ }^{\circ} \mathrm{C}$ for one hour. The weight of the catalyst (1.0 g; 20-30 mesh pellets size) and the methanol flow (25 $\mu \mathrm{L} / \mathrm{min}$ ) were optimized to achieve a space velocity (WHSV) of $1.2 \mathrm{~h}^{-1}$. Reaction 
products were analyzed on-line by gas chromatography with a chromatograph VARIAN CP3800. The device is equipped with two columns: (i) a capillary column Petrocol DH50.2 connected to a FID detector, and (ii) a packed column HayesepQ (2 m length, $3.17 \mathrm{~mm}\left(1 / 8^{\prime \prime}\right)$ of external diameter and $2 \mathrm{~mm}$ of internal diameter) connected to a TCD detector, in order to analyze hydrocarbons and oxygenated products, respectively.

\section{Results and discussion}

\subsection{Synthesis of SAPO-34 materials in the ionic liquid EMI}

One of the common problems in the hydrothermal synthesis of microporous AlPOs is the low structural specificity of the SDA [29]. A given structure-directing agent (SDA) molecule can direct the crystallization of several $\mathrm{AlPO}_{4}$-based structures [30], and additionally a particular structure, for instance $\mathrm{AlPO}_{4}-5$ or $\mathrm{AlPO}_{4}-11$, can be prepared with different SDAs [31]. Such low specificity is also extensive to the ionothermal systems, where IL plays two roles, solvent and SDA [5, 25].

Figure 1 compiles the powder X-ray diffraction patterns of different $\mathrm{AlPO}_{4}$ samples doped with different heteroatoms, i.e. $\mathrm{Si}, \mathrm{V}$ or $\mathrm{Ti}$, and crystallized in the ionic liquid EMI at $150{ }^{\circ} \mathrm{C}$ for $72 \mathrm{~h}$. The use of either TEOS or Aerosil 200 as Si source does not change the achieved phase AEL $\left(\mathrm{AlPO}_{4}-11\right)$, which is the same to that crystallized from a Si-free aluminophosphate gel under the same experimental conditions (PXRD pattern not shown). However, the presence of a small amount of either $\mathrm{V}$ or $\mathrm{Ti}$ directs the crystallization specifically to the desired CHA phase. Some more examples of the strong structure-directing effect of the V ions are included in Figure S1 (Supporting Information). Therefore, confirming the low phase-specificity of the ionic liquids as SDA in the preparation of the $\mathrm{AlPO}_{4}$-based microporous materials, Figure 1 indicates 
that such SDA role given by ILs is easily overcome by simply adding certain heteroatoms in low concentration, which could completely alter the phase distribution achieved in their absence. Figure 1 also shows the different PXRD patterns of the Sidoped $\mathrm{AlPO}_{4}$ samples prepared from gels with different water content as a consequence of the pretreatment before closing the corresponding autoclave. Despite no water was added to the synthesis media, the reactants $\mathrm{H}_{3} \mathrm{PO}_{4}$ and $\mathrm{HF}$ were added as aqueous solutions of 85 and $40 \mathrm{wt} . \%$, respectively incorporating some water in the synthesis media. Moreover, the ionic liquid EMI is highly hygroscopic, so it would probably adsorb some water from the atmosphere during the reactants weighting and gel preparation. It is already well-known the notable influence of the small traces of water in the phase distribution of the $\mathrm{AlPO}_{4}$-based systems ionothermally treated [5]. In this context, it is not surprising that the pretreatment of the SAPO gels at $50{ }^{\circ} \mathrm{C}$ (sample Si0.3-50C) and especially at $75{ }^{\circ} \mathrm{C}$ (sample Si0.3-75C) for two hours, favors the crystallization of a higher proportion of CHA-structured phases against that of structure AEL, what is in good agreement with the literature [5]. Nevertheless, no pure CHA materials were crystallized under the tested conditions. It must be noted that the nonpretreated sample Si0.3 is basically composed by phase AEL with no indications of the presence of CHA.

Since the highest specificity towards CHA-structured materials was achieved with the addition of the heteroatoms $\mathrm{V}$ and $\mathrm{Ti}$ (Figure 1), which seems to have a structuredirecting effect even stronger than the ionic liquid itself, a series of further experiments trying to incorporate simultaneously incorporate both $\mathrm{V}$ and $\mathrm{Si}$ into the $\mathrm{AlPO}_{4}-\mathrm{CHA}$ framework were designed. It must be pointed out that these experiments were carried out without any preheating treatment of the mixture, so the crystallization of AELstructured rather than CHA materials should be favored in the absence of V. The 
PXRD pattern of the sample V0.04Si0.1cl shown in Figure 2 indeed indicates the strong structure-directing effect of $\mathrm{V}$, as the quite low concentration of the heteroatom in the global mixture (V/Al molar ratio of 0.04 ) is enough to lead the crystallization exclusively towards the phase $\mathrm{CHA}$ even with $\mathrm{Si} / \mathrm{Al}$ molar ratios as high as 0.3 (PXRD pattern not shown).

These VAPSO-34 samples were light green, just like the above-described VAPO-34 and, in fact, like the typical color of the VAPO samples. That color indicates that at least part of $\mathrm{V}$ is in oxidation state +4 [32], which would mean that the achievement of the structure CHA in this VAPSO entails the introduction of some acidity generated by the substitution of $\mathrm{P}^{5+}$ ions by $\mathrm{V}^{4+}$ ones in a theoretical non-doped $\mathrm{AlPO}_{4}$ material. This acidity is additional to that given by the $\mathrm{Si}^{4+}$ incorporation and it is not desired in terms of the application of the catalysts in the MTO process and in the further interpretation of the obtained data.

To overcome this drawback, the ionothermal synthesis offers an elegant alternative, which is indeed impossible to be applied in hydrothermal conditions: to carry out the thermal treatment in open autoclaves. To the best of our knowledge, this alternative has not been used yet as a way of altering the chemistry of the ionothermal crystallization process. The PXRD patterns of the samples V0.04Si0.1op and V0.04Si0.3op presented in Figure 2 certify that the unique phase detected in the samples crystallized in open autoclaves is CHA, that is, they are VAPSO-34 materials, whereas the sample synthesized in the absence of $\mathrm{V}$ (sample Si0.1op) stills contains a non-negligible amount of AEL-structured materials as impurity. In addition, the pictures and the DRUV-vis spectra of the samples shown in Figure 3 indicate a color change in these samples, which varies from green when the samples are crystallized in closed autoclaves, to white when they are crystallized in open autoclaves. It is well-known that 
$\mathrm{V}$ can be incorporated in an $\mathrm{AlPO}_{4}$ framework in the oxidation states +4 and +5 , presumably in both cases substituting $\mathrm{P}^{5+}$ ions [32]. That color change could suggest that the $\mathrm{V}^{4+}$ ions contained in the samples prepared in closed autoclaves is oxidized to $\mathrm{V}^{5+}$. In good agreement with such color change, the UV region of the DR-UV-vis spectrum presented in Figure 3 ratifies the almost total disappearance of the d-d band in the sample V0.04Si0.1op. The same bands are very intense in their homologous sample V0.04Si0.1cl. An important consequence of the V oxidation state is that incorporated $\mathrm{V}^{4+}$ would generate Brönsted acidity (environments $\mathrm{V}^{4+}-\mathrm{OH}-\mathrm{Al}$ ) whereas $\mathrm{V}^{5+}$ do not affect the framework charge and do not introduced any Brönsted acidity (environments $\mathrm{V}^{5+}-\mathrm{O}-\mathrm{Al}$ ) additional to that given by $\mathrm{Si}^{4+}$ incorporation.

On the other hand, chemical analyses of the samples prepared in open autoclaves indicated that VAPO-34 or VAPSO-34 samples contain very scarce amount of V (Tables S1 and S2 of the Supporting Information). For instance, the sample V0.04cl had the composition $\mathrm{V}_{1.19} \mathrm{Al}_{48.9} \mathrm{P}_{49.91} \mathrm{O}_{2}$ whereas the composition of the sample V0.04op was $\mathrm{V}_{0.15} \mathrm{Al}_{49.88} \mathrm{P}_{49.97} \mathrm{O}_{2}$. In other words, the fact of crystallizing the samples in open autoclaves entails that the resultant samples are quite poor in $\mathrm{V}$, although $\mathrm{V}$ maintains its structure-directing role towards CHA topology.

\subsection{Structure of SAPO-34 prepared in the ionic liquid EMI: triclinic CHA}

Figure 4 shows the PXRD pattern before and after calcination of a SAPO-34 prepared by a conventional hydrothermal method [27] and a SAPO-34 prepared in the ionic liquid EMI. It is well-known that CHA structure gives very different PXRD patterns for different as-synthesized AlPOs. Even different CHA-structured materials have been denoted with different names $\left(\mathrm{AlPO}_{4}-34, \mathrm{AlPO}_{4}-44\right.$ and $\left.\mathrm{AlPO}_{4}-47\right)$ because they have very different PXRD patterns although, once calcined, their corresponding patterns are 
undistinguishable [33]. Nevertheless, two different CHA structures, both having the same $\mathrm{AlPO}_{4}$ composition but notable structural differences, do exist. The most common CHA structure has a crystalline system trigonal, whereas the other CHA structure, which is generally formed in the presence of fluoride ions, is triclinic [34, 35]. Both $\mathrm{AlPO}_{4}$-based CHA materials SIZ-4 [5] and SIZ-10 [25] prepared in ionic liquids are triclinic, probably due to the presence of HF in the synthesis media. Not surprisingly, the CHA samples prepared in this work are also triclinic (Figure 4), as the experimental procedure described here is based on that described for SIZ-4 [5]. Unlike the set of the CHA-structured $\mathrm{AlPO}_{4}-34, \mathrm{AlPO}_{4}-44$ and $\mathrm{AlPO}_{4}-47$ materials, the calcination of triclinic $\mathrm{AlPO}_{4}-34$ does not unify its structure with that of the trigonal CHA materials. On the contrary, they become even more different visually when calcined.

Although a possible interpretation of Figure 4 could conclude that calcination process is what causes the notorious changes in the PXRD pattern of the triclinic SAPO-34, in order to better understand these changes, a thermal diffraction experiment was carried out. Figure 5 shows the XRD patterns of a VAPO-34 material prepared in the ionic liquid EMI after being treated at different temperatures under dry air atmosphere. The temperature was increased from room temperature $\left(24{ }^{\circ} \mathrm{C}\right)$ to $550{ }^{\circ} \mathrm{C}$. After registering the PXRD pattern at room temperature, the second XRD pattern was acquired at $50{ }^{\circ} \mathrm{C}$, and then the following PXRD patterns were registered every $100{ }^{\circ} \mathrm{C}$. Once the PXRD pattern at $550{ }^{\circ} \mathrm{C}$ was registered, the sample was cooling down to $40{ }^{\circ} \mathrm{C}$, and finally it was exposed to the air atmosphere for one day. From the PXRD patterns of Figure 5, it can be inferred that the removal of SDA does not cause the structural changes clearly shown by X-ray diffraction between the as-prepared and the calcined triclinic SAPO-34. On the contrary, that change is due to the exposure of the calcined sample to the atmospheric air. Therefore, the hydration of SAPO-34 once their pores have been 
emptied by the calcination treatment is the most foreseeable reason behind the structural changes. The same conclusion was also found in the literature [34].

The trigonal CHA structure has 12 different $\mathrm{T}$ positions ( $\mathrm{P}$ and $\mathrm{Al}$ positions in the case of $\mathrm{AlPO}_{4}$-based materials) [34]. Such high number of $\mathrm{T}$ crystallographic positions increases the possibility of introducing different acidity in SAPO-34 by incorporating Si atoms, what is expected to have a remarkable effect in the catalytic properties of the material in any acid-catalyzed process such as the MTO process. Therefore, the following section, which describes the catalytic tests of some selected triclinic SAPO34 materials in MTO, is widely justified.

A complete multinuclear solid-state NMR study of this material has also been carried out. Figure 6A shows the ${ }^{31} \mathrm{P}$ MAS NMR spectra of the sample V0.04 with triclinic CHA structure in both as-synthesized and calcined forms. The ${ }^{31} \mathrm{P}$ MAS NMR spectrum of a conventional $\mathrm{AlPO}_{4}$-based material with trigonal structure $\mathrm{CHA}$ shows a unique signal centered at ca. $-30 \mathrm{ppm}$ [36], either before or after calcination, in good agreement with the unique tetrahedral site that possess this structure. Such ${ }^{31} \mathrm{P}$ chemical shift is typical of a phosphorous atom surrounded by $4 \mathrm{Al}$ atoms in an $\mathrm{AlPO}_{4}$ material. However, the ${ }^{31} \mathrm{P}$ MAS NMR spectrum of the as-synthesized sample V0.04 is dominated by three different signals at $-7,-24$ and $-29 \mathrm{ppm}$. The signal at $-7 \mathrm{ppm}$ suggests that some ${ }^{31} \mathrm{P}$ is linked (in their second coordination sphere) to at least one Al with coordination higher than four. It is presumable that $\mathrm{F}^{-}$ions are involved in the coordination of certain framework $\mathrm{Al}$ ions [34]. These $\mathrm{F}^{-}$ions would neutralize the EMI cations located within the CHA cage [37]. The spectrum of the as-prepared sample V0.04 is in good agreement with that published by Morris et al. [5] for the SIZ-4 material. 
${ }^{27}$ Al MAS NMR spectra of both as-prepared and calcined sample V0.04 are shown in Figure $6 \mathrm{~B}$. The spectrum of the as-prepared sample is in very good agreement with that reported for SIZ-4 [5]. As expected from the ${ }^{31} \mathrm{P}$ MAS NMR and from previous studies $[34,37]$, there are some octahedral $\mathrm{Al}$ atoms coordinated to two $\mathrm{F}^{-}$ions

The calcination induces important changes in the Al environments. 4-, 5- and 6-fold Al ions can be detected. The 6-fold $\mathrm{Al}$ appears at different chemical shift and has different shape than that found before calcination. It is quite probable that $\mathrm{F}^{-}$ions leave the samples during calcination and these octahedral $\mathrm{Al}$ is 4-coordinated to the framework and 2-coordinated with water molecules.

${ }^{13} \mathrm{C} \mathrm{CP}$ (cross-polarization) MAS NMR spectrum of the as-prepared sample V0.04, as well as the tentative assignment of the signals, are shown in Figure 6C. As expected, the cation EMI is found intact within the pores of the triclinic CHA. Furthermore, this assumption is also confirmed by the thermogravimetric analyses presented in Figure S3 (Supporting Information).

Figure 6D shows the ${ }^{19} \mathrm{~F}$ MAS NMR spectra of the sample V0.04, before and after being calcined. The very sharp and intense ${ }^{19} \mathrm{~F}$ signal found in the spectrum of the asprepared sample indicates the notable abundance of this nucleus in the sample. Indeed, the presence of $\mathrm{F}^{-}$ions seems to be essential to generate triclinic $\mathrm{CHA} \mathrm{AlPO}_{4}$-based materials. The presence of this anion has been indirectly inferred from the existence of octahedral Al environments (Figure 6B) in a water-free sample (Figure S3, Supporting Information). The calcination entails the practical removal of $\mathrm{F}^{-}$ions, and it was really hard to find some $\mathrm{F}^{-}$ions. This explains the poor signal-to-noise ratio of the spectrum of the calcined sample V0.04. Moreover, the main ${ }^{19} \mathrm{~F}$ signal is completely different to that attributed to the $\mathrm{F}^{-}$ions coordinated to $\mathrm{Al}$ atoms in the as-prepared sample. 
Some further characterization results of the triclinic CHA materials by means $\mathrm{N}_{2}$ adsorption/desorption isotherms at $-196{ }^{\circ} \mathrm{C}$ (Figure S2), thermogravimetric analysis (Figure S3), and Scanning Electron Microscopy (Figure S4) are given in Supporting Information to shed some light on the knowledge about this V-doped $\mathrm{AlPO}_{4}-34$ material with a triclinic CHA structure.

\subsection{VAPSO-34 prepared in the ionic liquid EMI as catalysts in the MTO process}

Three VAPSO-34 materials prepared in the ionic liquid EMI with systematic variation of the Si and V contents (Table 1) were tested in the methanol-to-olefins transformation. Previously, the samples were calcined at $550^{\circ} \mathrm{C}$ during 6 hours under air flow. The catalytic behavior of these materials was compared with that of the conventional (trigonal CHA) SAPO-34 and $\mathrm{AlPO}_{4}-34$. Some characterization results of the different physico-chemical properties of the calcined samples VAPSO-34 are also included and discussed at some extent in the Supporting Information. All catalysts have chabazite as the only crystalline phase detected by XRD (Figure S5). Of course, that CHA phase was trigonal for the conventional samples and triclinic for the samples prepared in EMI. The VAPSO-34 materials have different crystallinity and crystal size (Figure S5). Their textural properties $\left(\mathrm{S}_{\mathrm{BET}}\right.$ values are given in Table 1 and the isotherms in Figure $\mathrm{S} 6$ ) were relatively far from these reached by a Si-free VAPO-34 also prepared in the ionic liquid EMI $\left(S_{\mathrm{BET}}=637 \mathrm{~m}^{2} \cdot \mathrm{g}^{-1}\right.$, Figure $\left.\mathrm{S} 2\right)$. In any case, the textural properties of the materials do not correlate well with their performance in MTO reaction (Table 1), what suggests that the presence of $\mathrm{Si}$ atoms and their environment within the $\mathrm{AlPO}_{4}$ framework could also have outstanding influence, being the $\mathrm{AlPO}_{4}-34$ sample the one with lowest conversion among all the samples under the tested experimental conditions. 
Figure 7 shows the ammonia temperature-programmed desorption $\left(\mathrm{NH}_{3}-\mathrm{TPD}\right)$ profiles of the three selected VAPSO-34 catalysts. Some relevant data of these $\mathrm{NH}_{3}$-TPD profiles are given in Table 1. It could seem striking that the less crystalline and less microporous sample V0.08Si0.1 (Figures S5 and S6, Table 1) is however the most acidic one.

Furthermore, the sample V0.08Si0.1 is also the most active one tested sample in the MTO process (Table 1). That apparent oddness is suggested to be due to the fact that this sample could both be formed by smaller crystals and accept better $\mathrm{Si}$ incorporation, because of more abundant nucleation given in the $\mathrm{V}$-richer gel. This reasoning is discussed more widely in the Supporting Information.

Figure 8 shows the methanol conversion and selectivity to dimethylether (DME) given by the VAPSO-34 catalysts at different reaction times (5 and 60 minutes). Despite the conversion of methanol over the three catalysts prepared in EMI is lower at longer reaction time, the selectivity to olefins increases after the first minutes on stream whereas the DME trend is opposite. All the catalysts obtained by the ionothermal method are able to convert methanol under the tested conditions, so are active as acid catalyst. Comparing the three catalysts in Figure 8, the sample V0.08Si0.1 can be considered as the most interesting one, as it overcomes the other two in the three most important aspects of the reaction: methanol conversion, a higher stability (made clear by a higher rate of conversion after 60 minutes of reaction), and a higher selectivity to hydrocarbons (lower selectivity to DME after 60 minutes on stream). Even though the catalytic performance in terms of conversion of methanol of all these materials is far from reaching that of the conventional SAPO-34 (Table 1), it is noteworthy the superior activity and stability of these catalysts compared with the conventional $\mathrm{AlPO}_{4}-34$ (Table 1). This suggests the generation of certain acidic centers active in the MTO process in 
the VAPSO-34 samples. In fact, the three ionothermally-prepared catalysts gave intermediate acidity between the conventional SAPO-34 and $\mathrm{AlPO}_{4}-34$, according to the $\mathrm{NH}_{3}$-TPD results

Considering the data from Table 1 and Figure 8, the catalyst V0.08Si0.1 was selected to compare the selectivity to the different olefins with those obtained with the conventional SAPO-34 and $\mathrm{AlPO}_{4}-34$. Figure 9 shows the selectivity to olefins given by the three mentioned catalysts under the same reaction conditions $\left(400{ }^{\circ} \mathrm{C}, 1.2 \mathrm{~h}^{-1}\right.$, after 60 minutes of reaction). Although the conversion of the three catalysts is quite different at the selected time on stream (Table 1), the selectivities are compared considering that the selectivity to olefins is scarcely altered along the reaction time if the catalyst continues being active [27].

The selectivities of both catalysts containing Si included in Figure 9 follow the same trend (propylene > ethylene > C4 olefins), whereas the trend given by $\mathrm{Si}$-free $\mathrm{AlPO}_{4}-34$ is different (ethylene > propylene > C4 olefins). The similarity in the selectivities displayed by the $\mathrm{Si}$ containing samples suggests that at least part of $\mathrm{Si}$ has been incorporated in the triclinic SAPO-34 crystallized in the ionic liquid EMI. On the other hand, it is also significant the increase in selectivity to $\mathrm{C} 4$ olefins given by the sample V0.08Si0.1 (24.2\%) compared to the provided by the conventional SAPO-34 (15.7\%). That higher selectivity to $\mathrm{C} 4 / \mathrm{C} 2$ olefins ratio is quite encouraging considering the recent industrial demand, which prioritizes propylene and C4 olefins against ethylene. Another important aspect is the fact that triclinic SAPO-34 alters not just the activity but the selectivity given by the conventional trigonal SAPO-34, which could mean a new feature of the catalyst to be taken into account when designing a catalyst, and could help to shed light on some not well understood mechanistic features of the MTO process, 
which still persists despite the great and continuous efforts made to clarify them $[13,38$, 39].

\section{Conclusions}

The preparation of SAPO-34 under ionothermal conditions is described. The direct addition of the different $\mathrm{Si}$ sources (fumed $\mathrm{SiO}_{2}$ or tetraethyl orthosilicate) to the mixture otherwise able to lead $\mathrm{AlPO}_{4}-34$, entails the (co-)crystallization of AELstructured materials. To reach the objective, two different alternative strategies were successful at some extent: (i) the use of $\mathrm{V}$ as co-heteroatom, which possesses great structure-directing effect to CHA materials even when added at low proportion; and (ii) the crystallization of the IL-based mixtures in open autoclaves, which somehow manages to lead the crystallization of SAPO-34 materials basically free of any $\mathrm{V}^{4+}$. The so-synthetized VAPSO-34 materials had the infrequent triclinic CHA structure since they were prepared in the presence of HF. Moreover, the so-prepared VAPSO-34 catalysts are white unlike their homologues prepared in closed autoclaves, so not Brönsted acidity due to $\mathrm{V}$ incorporation is expected. To the best of our knowledge, no triclinic SAPO-34 materials have been tested in the per-excellence reaction of these materials, the conversion of methanol to olefins (MTO). In the catalytic tests carried out in this work, it is made clear that these triclinic SAPO-34 materials gave higher selectivity to C4 olefins than the conventional trigonal SAPO-34, and lower ethylene was produced, what is in good consonance with the actual industrial demands.

\section{Acknowledgments}


This work has been partially financed by the Spanish State Research Agency (Agencia Española de Investigación, AEI) and the European Regional Development Fund (Fondo Europeo de Desarrollo Regional, FEDER) through the Project MAT2016-77496-R (AEI/FEDER, UE) and Project MAT2012-31127. IPH acknowledges CSIC for a PhD Jae-Predoc fellowship.

\section{References}

[1] T. Maesen, Stud. Surf. Sci. Catal. 168 (2008) 1 - 12.

[2] C.S. Cundy, P.A. Cox, Chem. Rev. 103 (2003) 663.

[3] X. Meng, F.S. Xiao, Chem. Rev. 114 (2014) 1521-1543

[4] B. Wu, W. Liu, Y. Zhang, H. Wang, Chem. Eur. J. 15 (2009) 1804-1810.

[5] E.R. Cooper, C.D. Andrews, P.S. Wheatley, P.B. Webb, P. Wormald, R.E. Morris, Nature 430 (2004) 1012-1016.

[6] E.R. Cooper, C.D. Andrews, P.S. Wheatley, P.B. Webb, P. Wormald, R.E. Morris, Stud. Surf. Sci. Catal. 158A (2005) 247-254.

[7] X. Sun, J. King, J.L. Anthony, Chem. Eng. J. 147 (2009) 2-5.

[8] I. Lezcano-González, M.G. O'Brien, M. Počkaj, M. Sánchez-Sánchez, A.M. Beale, Microporous Mesoporous Mater. 240 (2017) 117-122.

[9] Y. Lorgouiux, M. Dodin, J.L. Paillaud, P. Caullet, L. Michelin, L. Josien, O. Ersen, N. Bats, J. Solid State Chem. 182 (2009) 622-629.

[10] A. Rojas, M.A. Camblor, Angew. Chem. Int. Ed. 51 (2012) 3854-3856.

[11] P.S. Wheatley, P.K. Allan, S.J. Teat, S.E. Ashbrook, R.E. Morris, Chem. Sci. 1 (2010) 483-487. 
[12] X.H. Zhao, H. Wang, C.X. Kang, Z.P. Sun, G.X. Li, X.L. Wang, Microporous Mesoporous Mater. 151 (2012) 501-505.

[13] P. Tian, Y.X. Wei, M. Ye, Z.M. Liu, ACS Catal. 5 (2015) 1922-1938.

[14] S. Wilson, P. Barger, Microporous Mesoporous Mater. 29 (1999) 117-126.

[15] J.Q. Chen, A. Bozzano, B. Glover, T. Fuglerud, S. Kvisle, Catal. Today 106 (2005) 103-107.

[16] D. Chen, K. Moljord, A. Holmen, Microporous Mesoporous Mater. 164 (2012) 239-250.

[17] T. Álvaro-Muñoz, C. Márquez-Álvarez, E. Sastre, Catal. Today 179 (2012) 2734.

[18] T. Álvaro-Muñoz, C. Márquez-Álvarez, E. Sastre, Appl. Catal. A-Gen. 472 (2014) 72-79.

[19] T. Álvaro-Muñoz, E. Sastre, C. Márquez-Álvarez, Catal. Sci. Technol. 4 (2014) 4330-4339.

[20] M. Sedighi, J. Towfighi, Fuel 153 (2015) 382-392.

[21] Z. Li, J. Martínez-Triguero, P. Concepción, J. Yu, A. Corma, Phys. Chem. Chem. Phys. 15 (2013) 14670-14680.

[22] Z. Li, J. Martínez-Triguero, J. Yu, A. Corma, J. Catal. 329 (2015) 379-388.

[23] D. Fan, P. Tian, S.T. Xu, Q.H. Xia, X. Su, L. Zhang, Y. Zhang, Y.L. He, Z.M. Liu, J. Mater. Chem. 22 (2012) 6568-6574.

[24] Y. S. Zhang, M. Pei, H. Zhi-Ping, J. X. Fan, L. Guan-Feng, J. Z. Zang, H. B. Yu, Chinese Patent CN103553075B (2015).

[25] E.R. Parnham, R.E. Morris, Chem. Mater. 18 (2006) 4882-4887.

[26] A.M. Rouhi, Chem. Eng. News 93 (2015) 30-31. 
[27] T. Álvaro-Muñoz, C. Márquez-Álvarez, E. Sastre, Catal. Today 213 (2013) 219225.

[28] I. Pinilla-Herrero, C. Márquez-Álvarez, E. Sastre, Catal. Today 277 (2016) 2936.

[29] M. Sánchez-Sánchez, G. Sankar, Stud. Surf. Sci. Catal. 154 (2004) 1021-1027.

[30] A.F. Ojo, L.B. McCusker, Zeolites 11 (1991) 460-465.

[31] S.T. Wilson, B.M. Lok, C.A. Messina, T.R. Cannan, E.M. Flanigen, J. Am. Chem. Soc. 104 (1982) 1146-1147.

[32] T. Blasco, L. Fernández, A. Martínez-Arias, M. Sánchez-Sánchez, P. Concepción, J.M.L. Nieto, Microporous Mesoporous Mater. 39 (2000) 219-228.

[33] N. Li, Y.F. Ma, W.B. Kong, N.J. Guan, S.H. Xiang, Microporous Mesoporous Mater. 115 (2008) 356-363.

[34] A. Tuel, S. Caldarelli, A. Meden, L.B. McCusker, C. Baerlocher, A. Ristic, N. Rajic, G. Mali, V. Kaucic, J. Phys. Chem. B 104 (2000) 5697-5705.

[35] O.B. Vistad, D.E. Akporiaye, F. Taulelle, K.P. Lillerud, Chem. Mater. 15 (2003) 1639-1649.

[36] Y. Watanabe, A. Koiwai, H. Takeuchi, S.A. Hyodo, S. Noda, J. Catal. 143 (1993) 430-436.

[37] M.M. Harding, B.M. Kariuki, Acta Crystallogr. Sect. C-Cryst. Struct. Commun. 50 (1994) 852-854.

[38] W.L. Dai, C.M. Wang, M. Dyballa, G.J. Wu, N.J. Guan, L.D. Li, Z.K. Xie, M. Hunger, ACS Catal. 5 (2015) 317-326.

[39] U. Olsbye, S. Svelle, K.P. Lillerud, Z.H. Wei, Y.Y. Chen, J.F. Li, J.G. Wang, W.B. Fan, Chem. Soc. Rev. 44 (2015) 7155-7176. 


\section{Table 1}

Summary of the physico-chemical properties of the calcined CHA-structured catalysts tested in the MTO process and their conversion in that process.

\begin{tabular}{|c|c|c|c|c|c|}
\hline \multirow{2}{*}{ Catalyst } & \multirow{2}{*}{$\begin{array}{c}\text { Si content } \\
(\%)^{\mathrm{a}}\end{array}$} & \multirow{2}{*}{$\begin{array}{c}\mathrm{S}_{\mathrm{BET}} \\
\left(\mathrm{m}^{2} \cdot \mathrm{g}^{-1}\right)\end{array}$} & \multicolumn{2}{|c|}{$\mathrm{NH}_{3}-\mathrm{TPD}$} & \multirow{2}{*}{$\begin{array}{c}\text { Conversión } \\
(\%)^{\mathrm{c}}\end{array}$} \\
\hline & & & $\operatorname{Tmax}\left({ }^{\circ} \mathrm{C}\right)^{\mathrm{b}}$ & $\mathrm{mmol} \mathrm{NH}_{3} / \mathrm{g}$ & \\
\hline $\mathrm{AlPO}_{4-34}$ & 0 & $52^{\mathrm{d}}$ & - & - & 18 \\
\hline Conv. SAPO-34 & 0.1 & 590 & - & - & 96 \\
\hline V0.04Si0.1 & 0.1 & 447 & 256 & 0.115 & 28 \\
\hline V0.08Si0.1 & 0.1 & 340 & 262 & 0.192 & 45 \\
\hline V0.04Si0.3 & 0.3 & 370 & 259 & 0.074 & 27 \\
\hline \multicolumn{6}{|c|}{${ }^{\mathrm{a}} \%$ molar of $\mathrm{Si}=\mathrm{Si} /(\mathrm{Si}+\mathrm{Al}+\mathrm{P}) \cdot 100$ in the gel. } \\
\hline \multicolumn{6}{|c|}{${ }^{\mathrm{b}}$ Temperature at which the maxima TCD intensity was detected. } \\
\hline \multicolumn{6}{|c|}{${ }^{\mathrm{c}}$ Conversion after 60 minutes of reaction at $400{ }^{\circ} \mathrm{C}$ and $\mathrm{WHSV}=1.2 \mathrm{~h}^{-1}$. } \\
\hline \multicolumn{6}{|c|}{${ }^{\mathrm{d}}$ This low surface was accompanied by a strong decrease in the crystallinity during } \\
\hline
\end{tabular}




\section{Figure Captions}

Figure 1. XRPD patterns of the $\mathrm{AlPO}_{4}$-based samples doped with $\mathrm{Si}, \mathrm{V}$ or $\mathrm{Ti}$ ionothermally crystallized in the ionic liquid EMI. The name of the sample is indicated on the left and the achieved phase(s) on the right.

Figure 2. XRPD patterns of the samples SAPO and VAPSO ionotherrmally crystallized in the ionic liquid EMI with either the open or closed autoclaves. The name of the sample is indicated on the left and the achieved phase(s) on the right.

Figure 3. UV region of the DR-UV-vis spectra of the samples V0.04Si0.1 prepared in the ionic liquid EMI in closed (red) and open (blue) autoclaves. The spectrum of the sample Si0.1op is also shown for comparison purposes.

Figure 4. XRPD patterns of a VAPSO-34 (black) and a conventional SAPO-34 (red) prepared in the ionic liquid EMI and by a conventional method, respectively, before (normal line) and after (bold line) calcination. The simulated XRPD patterns (blue) of a triclinic (bottom) and a trigonal (top) are also shown to facilitate the phase identification.

Figure 5. PXRD patterns of a VAPSO-34 material registered at different temperatures under flow of dry air. Either the temperature or any other data related to the registration conditions are indicated on the right.

Figure 6. (A): ${ }^{31} \mathrm{P}$ MAS NMR of sample V0.04 before (black line) and after (red)

calcination. The ${ }^{31} \mathrm{P}$ chemical shift values of the most intense signals are indicated in each spectra. (B): ${ }^{27} \mathrm{Al}$ MAS NMR of sample V0.04 before (black line) and after (red) calcination. The ${ }^{27} \mathrm{Al}$ chemical shift values of the most intense signals are indicated in each spectra. (C): ${ }^{13} \mathrm{C}$ CP MAS NMR of the as-synthesized sample V0.04. The chemical formula of the ionic liquid EMI chloride is also shown. Red letters indicates the tentative assignment of the all signals. (D): ${ }^{19} \mathrm{~F}$ MAS NMR spectra of the assynthesized (black) and calcined (red) sample V0.04. The ${ }^{19} \mathrm{~F}$ chemical shift of the most 
intense signals of each spectrum is indicated. Asterisks denote spinning side bands. Both spectra were normalized.

Figure 7. $\mathrm{NH}_{3}-\mathrm{TPD}$ profiles of the three VAPSO-34 catalysts.

Figure 8. Methanol conversion (solid columns) and selectivity to DME (striped columns) 400 ${ }^{\circ} \mathrm{C}$ after 5 minutes (red columns) o 60 minutes (blue columns) of the indicated catalysts.

Figure 9. Selectivity to ethylene (green columns), propylene (blue) and C4 olefins (orange) in the MTO process at $400{ }^{\circ} \mathrm{C}$ for 60 minutes given by the catalysts V0.08Si0.1 (left), conventional SAPO-34 (middle) and conventional $\mathrm{AlPO}_{4}-34$ (right). 
Figure 1

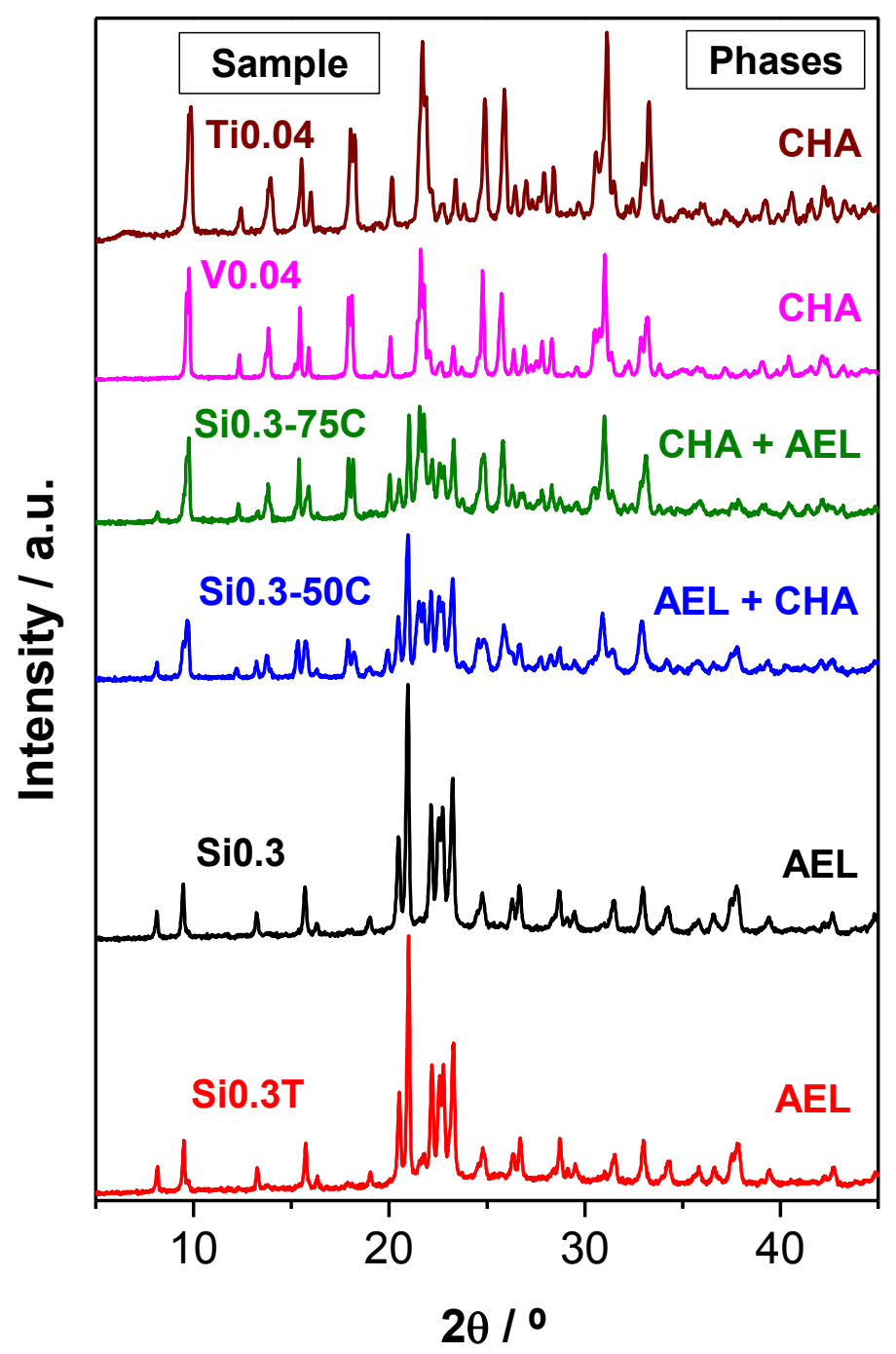


Figure 2

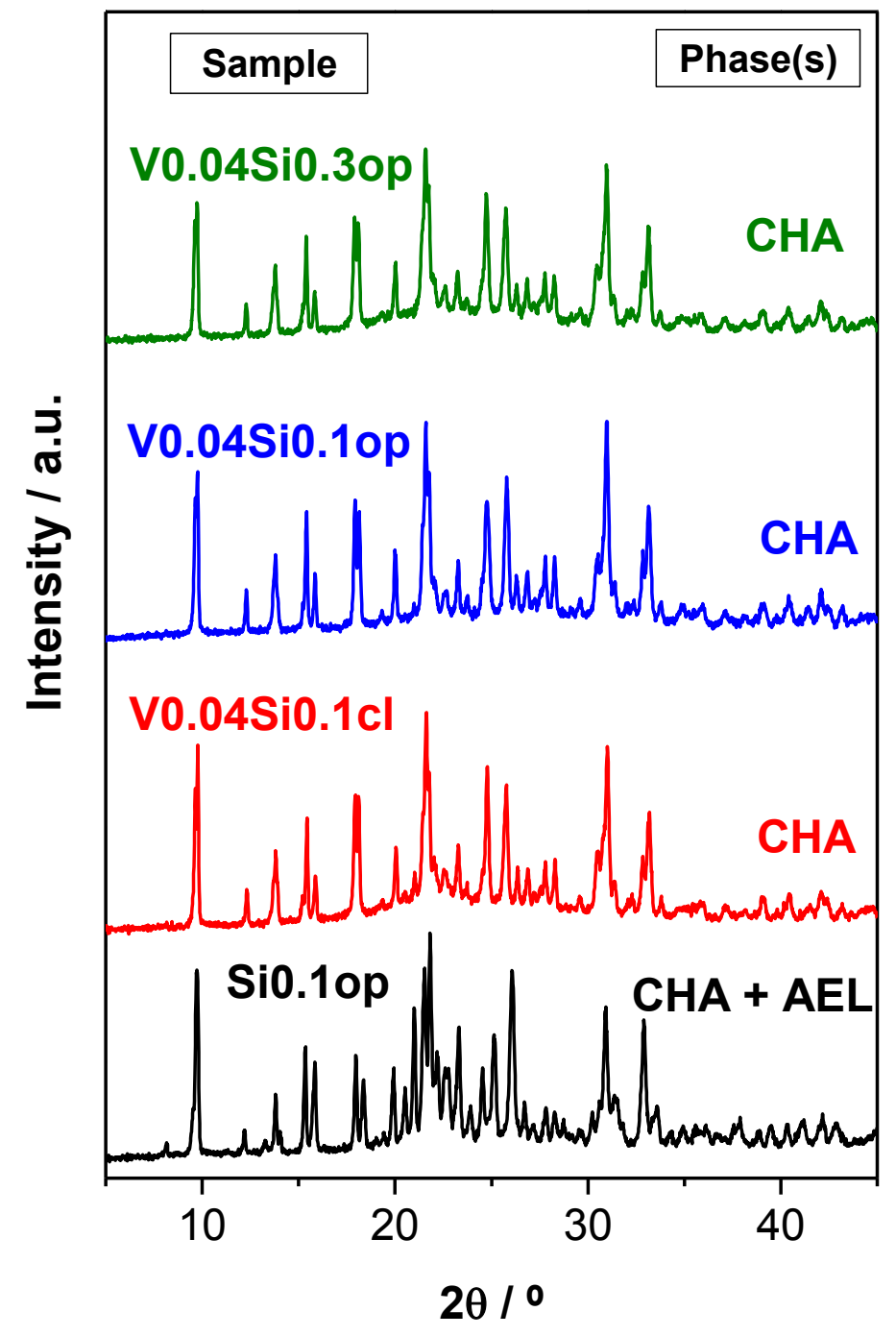


Figure 3

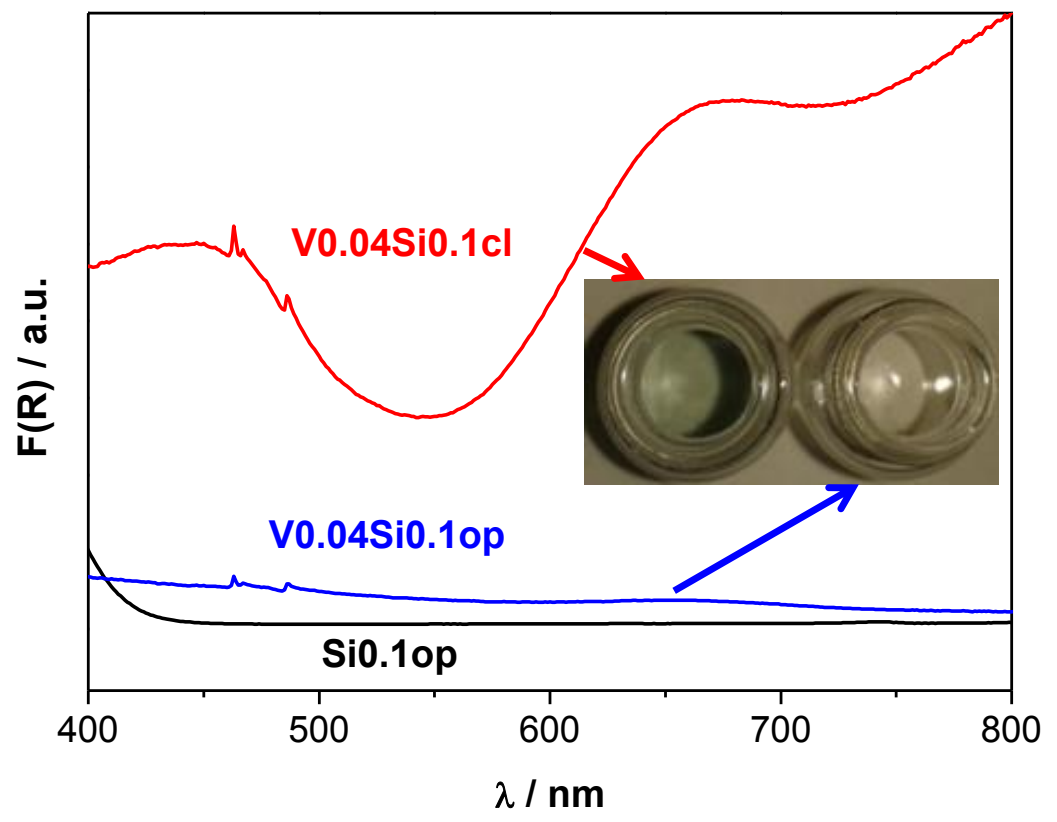


Figure 4

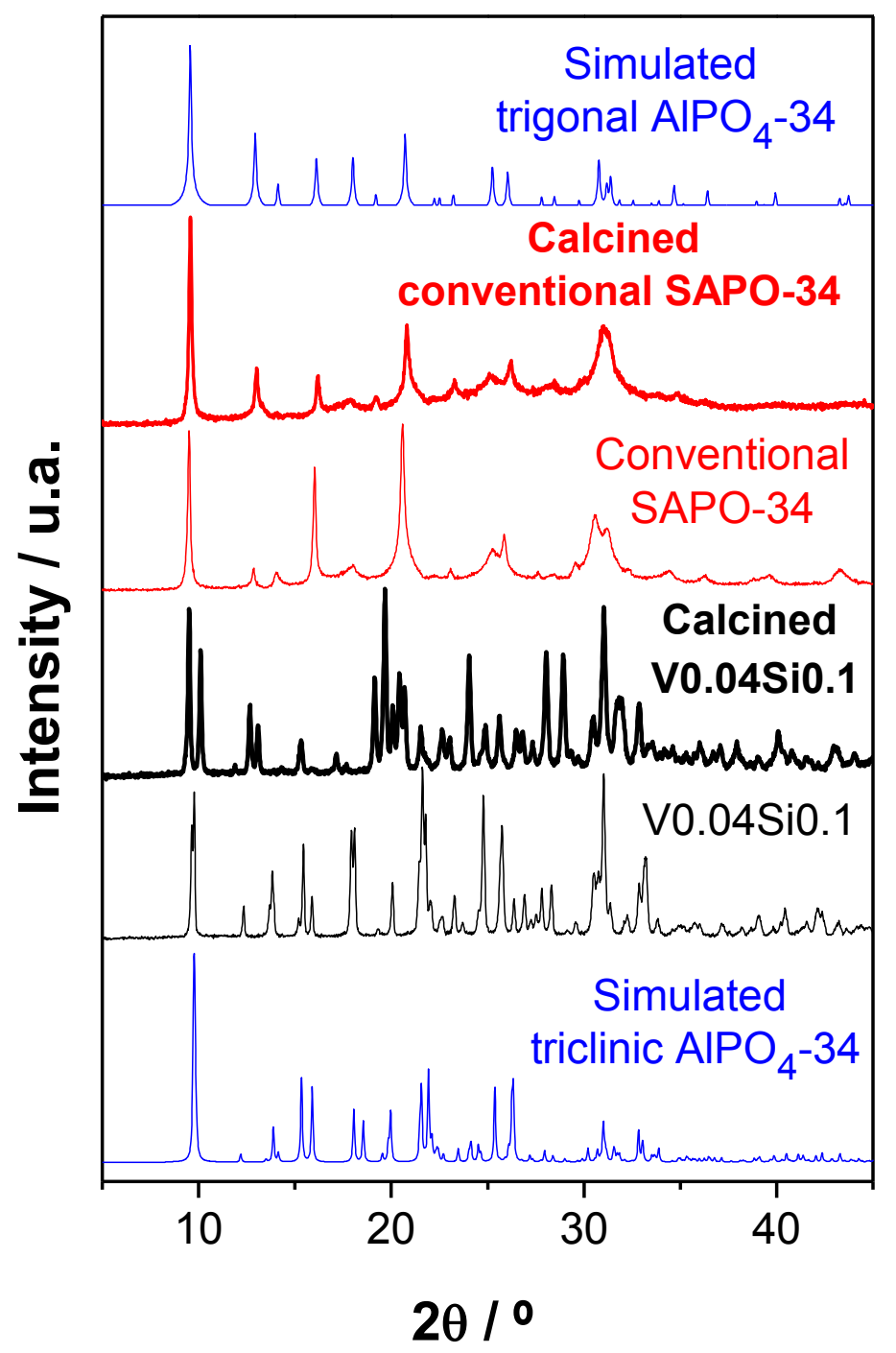


Figure 5

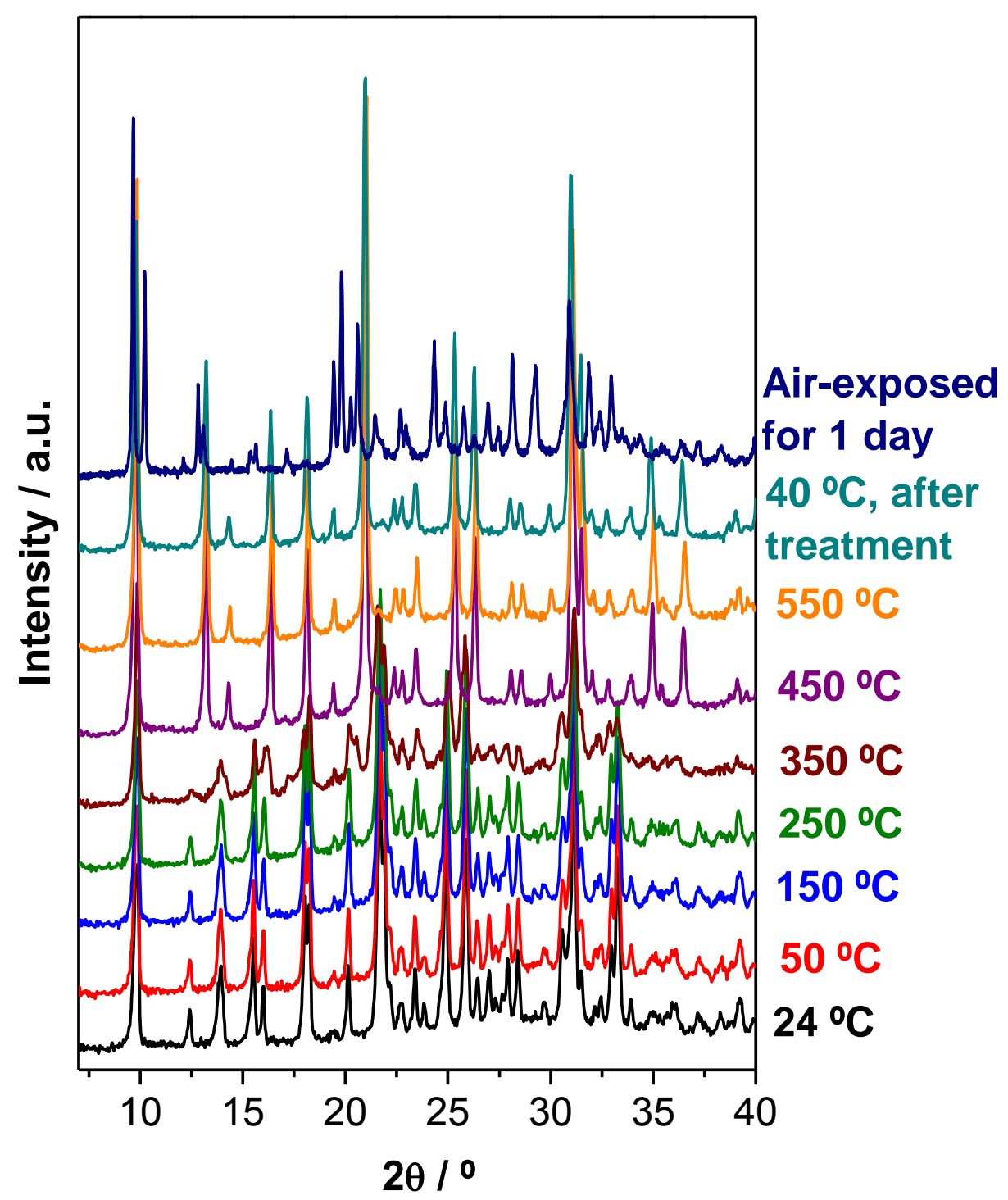


Figure 6

A
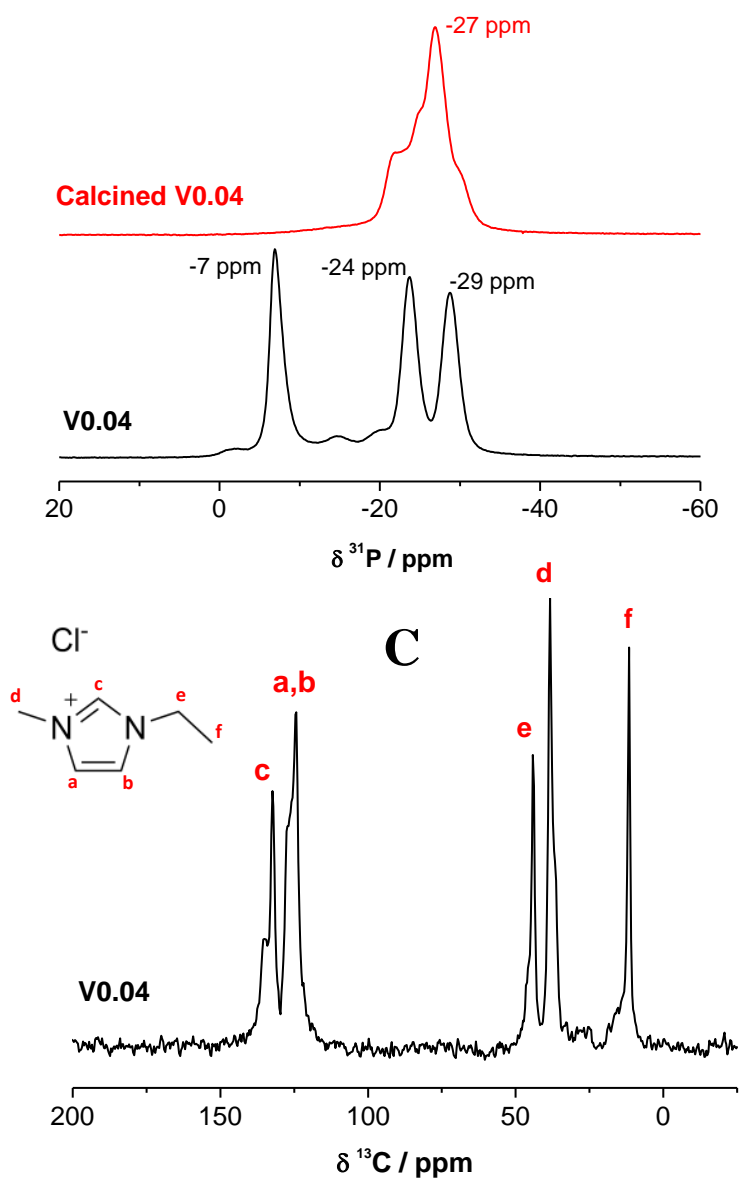

B
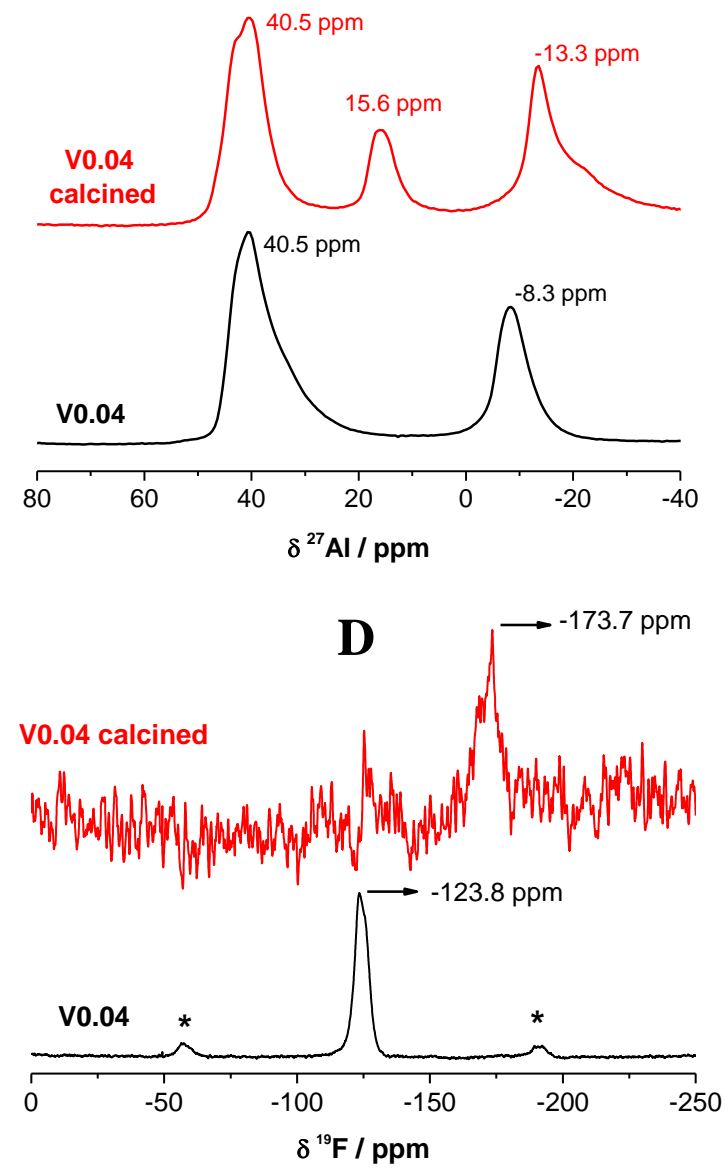
Figure 7

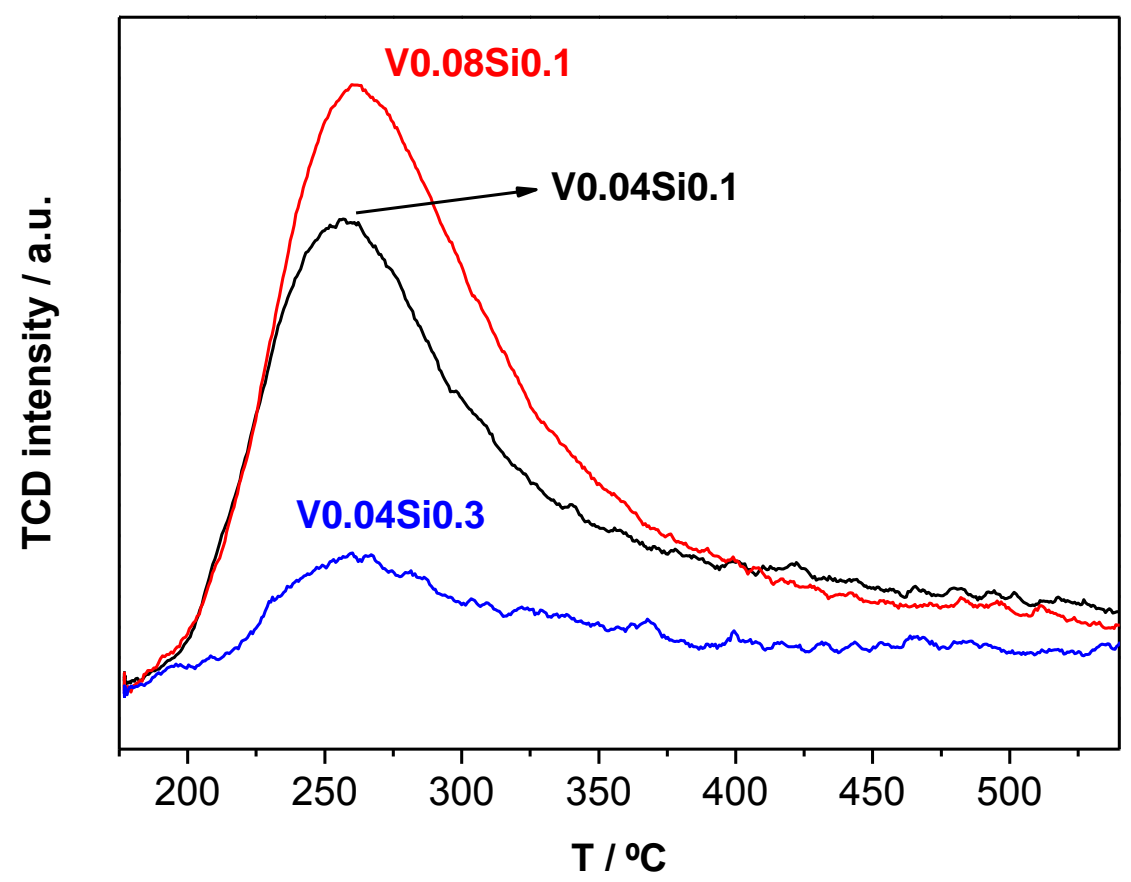


Figure 8

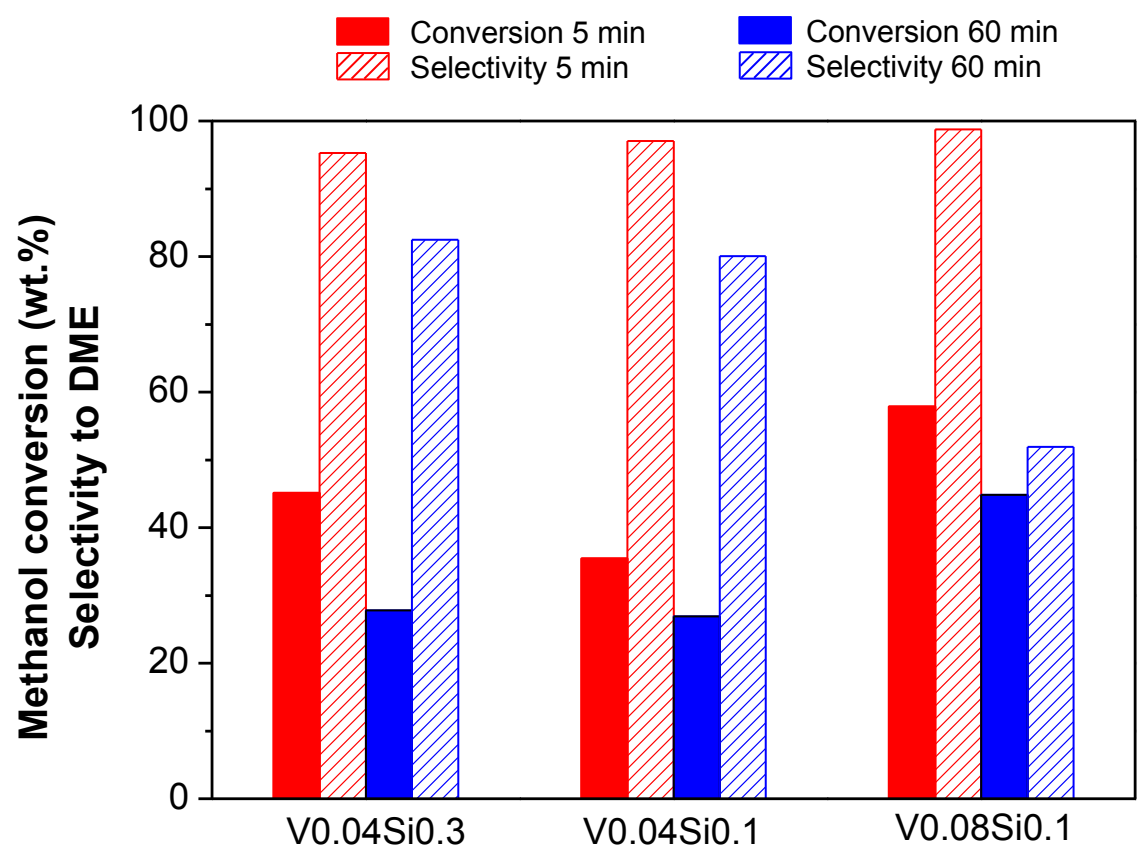


Figure 9

$1.2 \mathrm{~h}^{-1} / 400 \stackrel{\circ}{\mathrm{C}} / 60 \mathrm{~min}$

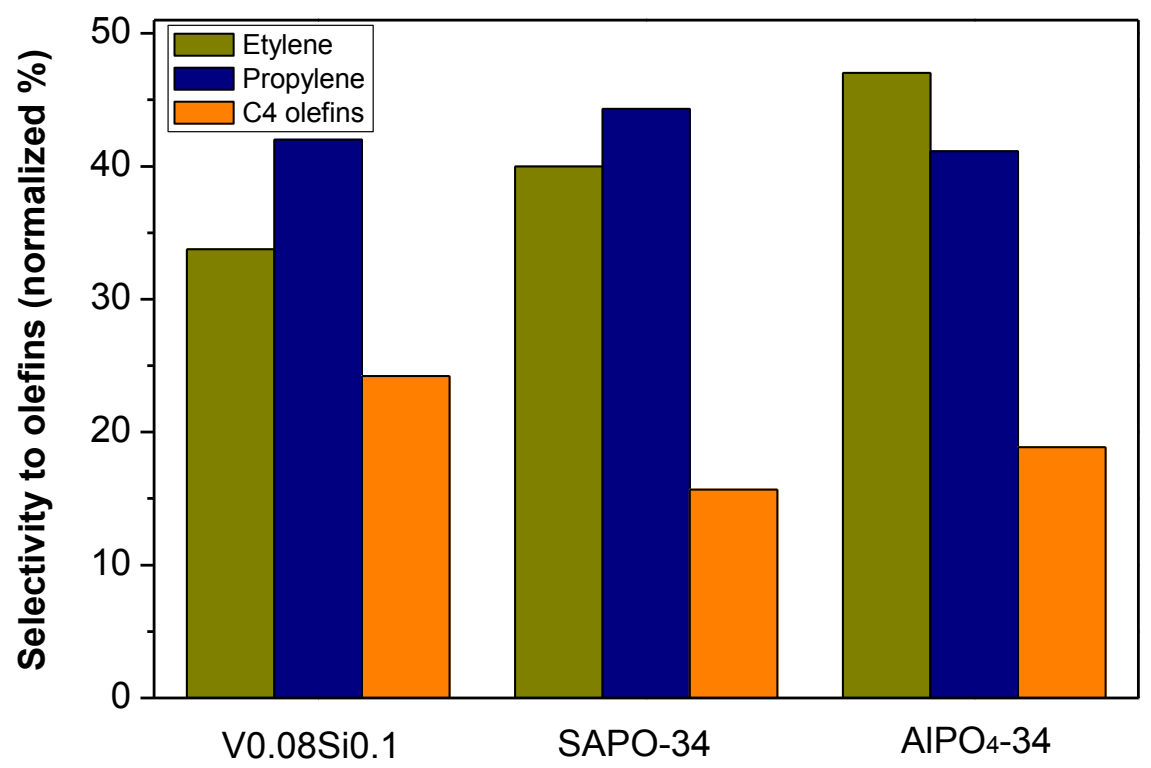

